\title{
Burden of corticosteroids in children with asthma in primary care: retrospective observational study
}

\author{
Suzie Ekins-Daukes, Colin R Simpson, Peter J Helms, Michael W Taylor, James S McLay
}

Department of Medicine and Therapeutics, University of Aberdeen, Foresterhill, Aberdeen AB25 2ZD Suzie Ekins-Daukes PhD student James S McLay senior lecturer, medicine and theraputics

Department of General Practice and Primary Care, University of Aberdeen

Michael W Taylor senior lecturer

Department of Child Health, University of Aberdeen

Colin R Simpson research assistant

Peter J Helms professor of paediatric

Correspondence to: J S McLay j.mclay@abdn.ac.uk

BMJ 2002;324:1374
In primary care, asthma and rhinitis are common paediatric comorbidities for which long term inhaled or nasal corticosteroid may be prescribed. Atopic children may receive both, resulting in high cumulative doses of topical corticosteroids and increasing the risk of adverse effects.

From 185 general practices in Scotland, we identified the number of children who were chronically prescribed both an inhaled and a nasal corticosteroid and calculated their total daily steroid burden between 1 November 1999 and 31 October 2000.

\section{Method and results}

Computer data about the prescribing of inhaled and nasal preparations to children between 1 November 1999 and 31 October 2000 was collected by 185 of 850 Scottish general practices currently using the general practice administration system for Scotland (software previously validated for completeness and accuracy). ${ }^{1}$

We identified all repeat prescriptions for inhaled and nasal corticosteroid in three age bands $(0-4,5-11$, and $12-16$ years) and calculated the prescribed dose of steroid preparations for each child. General practitioners often prescribe a dose range-for example, two puffs, two to four times daily-for corticosteroids (49\% of children were prescribed a dose range rather than a specific dose): we consider potential corticosteroid intake as a dose equivalent to beclomethasone dipropionate (by multiplying budesonide, mometasone, and triamcinolone doses by 1.5 and fluticasone propionate and flunisolide by two, and the potential maximum and minimum daily steroid dose expressed as the median and interquartile range for a beclomethasone equivalent dose.

Of the 177752 children registered with the 185 practices, 8913 children (5.1\%) were chronically prescribed an inhaled corticosteroid. A total of 560 $(6.3 \%)$ also had a repeat prescription for an nasal corticosteroid: 17 in the 0-4 year group, 240 in the 5-11 year group, and 303 in the 12-16 year group, equating to prevalence rates per 1000 children registered with a general practitioner of $0.36,3.2$, and 5.5 children aged $0-4,5-11$, and $12-16$ years.

The daily dose ranges equivalent to beclomethasone (figure) were $350-2400 \mu \mathrm{g}, 265-3400 \mu \mathrm{g}$, and 300$4800 \mu \mathrm{g}$ for the $0-4,5-11$, and 12-16 year olds. The relative contributions of the two types of steroid preparations to total daily steroid intake were similar for all age groups, with nasal corticosteroid accounting for at least a third of the total daily intake.

\section{Comment}

When treating children with an inhaled and a nasal corticosteroid, general practitioners should consider the potential cumulative steroid burden. In adults, side effects due to inhaled corticosteroid are minimal at low dose but substantial at high doses. ${ }^{2}$ It is difficult to

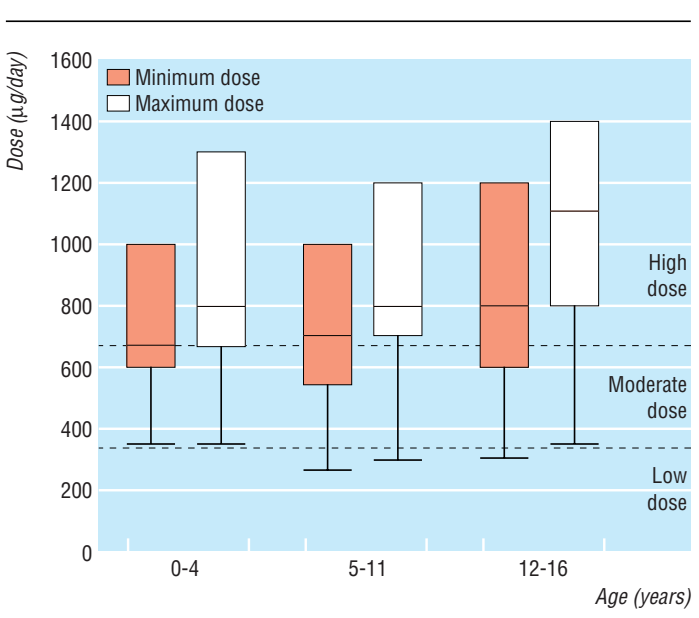

Total daily steroid burden in children prescribed inhaled and nasal corticosteroids. Plots show medians, 25th and 75th centiles, and lower ranges

define low or high corticosteroid use; however, it has been said that a dose of beclomethasone of up to 336 $\mu \mathrm{g} /$ day could be considered as low, 378-672 $\mu \mathrm{g} /$ day as moderate, and above $672 \mu \mathrm{g} /$ day as high. ${ }^{3}$

Using these definitions, between 341 (61\%, minimum steroid dose used) and 462 (83\%, maximum steroid dose used) of the total 560 children identified as prescribed chronic inhaled and nasal corticosteroids may be subject to chronic high dose steroid use (figure).

The potential long term toxicity of chronic corticosteroid use in children is unclear: most children with asthma eventually attain normal height, even receiving moderate corticosteroid doses, despite reports of adrenal suppression and reduced growth velocity. ${ }^{4-5}$ When more than one steroid preparation is prescribed, the total steroid burden should be calculated and consideration given to other treatment.

Contributors: JM had the idea and framed the questions with SE-D. CS and SE-D analysed the data. SE-D and JM wrote the paper with contributions from PH and MT. MT is guarantor.

Funding: CS was supported by Merck Sharp \& Dohme, UK. The continuous morbidity recording project is supported by the Information Services Directorate of the Scottish Executive Department of Health.

Competing interests: None declared.

1 Whitelaw FG, Taylor RJ, Nevin SL, Taylor MW, Milne RM, Watt AH. Completeness and accuracy of morbidity and repeat prescribing records held on general practice computers in Scotland. Br J Gen Pract 1996;46:181-6.

2 Wagener JS, Wojtczak HA. Inhaled steroids in children: risks versus rewards. J Pediatr 1998;132:381-3.

3 National Asthma Education and Prevention Program. Expert panel report 2: guidelines for the diagnosis and management of asthma. Bethesda: National Institutes of Health, 1997. (Publication No 97-4051.)

4 Patel L, Wales JK, Kibirige MS, Massarano AA, Couriel JM, Clayton PE Symptomatic adrenal insufficiency during inhaled corticosteroid treatment. Arch Dis Child 2001;85:330-4.

5 Agertoft L, Pedersen S. Effect of long-term treatment with inhaled budesonide on adult height in children with asthma. $N$ Engl J Med 2000;343:1064-9.

(Accepted 12 December 2001) 